\title{
A plea for diachronic necessity: the case of language acquisition
}

By VINCENT GRONDIN

Collège Édouard-Montpetit (Québec) - FQRSC

According to a widespread reading of Philosophical Investigations, Wittgenstein's conception of language relies on a substantial account of how language is actually learned by children. ${ }^{1}$ Originating from a set of papers written by Norman Malcolm $(1954,1982,1989)$, this exegetical tradition has been prompted by several passages where Wittgenstein claims that our language is an "extension" and a "refinement" of our instinctive behaviours ( $P I \S 244, \mathrm{Z} \S 454, C V$ p. 31, OC $\$ 538$ and $\S 204$ ). Although Wittgenstein has always stressed the gulf lying between philosophical investigations and empirical sciences, these passages have moved a lot of scholars to draw the conclusion that Wittgenstein is actually committed to an implicit theory of language acquisition that should be taken into account in contemporary debates (HARRÉ \& ROBINSON 1997, MOYAL-SHARROCK 2000). Among these ethologist readers of Wittgenstein, Canfield is probably the most radical: in a sequence of stimulating articles, he argues that ethological research should be conducted in accordance with Wittgenstein's intuition about the learning language process $(1993,1995,1996)$.

This reading has, however, been seriously challenged for reasons that are mainly historical and exegetical (LOUGHLIN 2014, DROMM 2003, 2006). Among all objections encountered by the ethological reading of Wittgenstein, the most serious one is the fact that he states frequently that

\footnotetext{
${ }^{1}$ I have discussed a former version of this paper with Stephen Mulhall. I would like to thank him for his insightful comments and challenging objections. The discussion that followed my presentation of this paper at the conference of Liège has also helped me to clarify my thoughts.
} 
philosophy should not try to explain the genesis of concepts ${ }^{1}$ or to reconstruct the actual history of the learning language process ${ }^{2}$. In a similar vein to that argumentative strategy, it would be quite easy to make the case that the ethological conception of language acquisition corresponds to a position held by a large array of authors (SPENGLER 1927 : 113-153; RUSSELL 2006 : 113; RICHARD \& ODGEN 1956) that had been strongly criticized by Wittgenstein at the beginning of the $30 \mathrm{~s}^{3}$. However, from a philosophical point of view, the ethological reading of Wittgenstein raises a lot of philosophical difficulties that have not been discussed yet. The main goal of this paper is to fill this gap by unfolding the philosophical issues related to that historical debate. More precisely, this paper aims to show that the ethological interpretation should also be challenged on philosophical grounds. My claim will be that it is not possible to give a coherent formulation of the ethological account in the context of Wittgenstein's mature philosophy without casting some doubts on the universal validity of the notion of "grammatical rule".

This paper will accordingly be divided into four different parts: 1/A brief description of what I mean by the Ethological Account of language is

${ }^{1}$ In Philosophical Investigations, Wittgenstein makes the point that the historical genesis of a concept should not be taken into account in the context of a philosophical investigation (PI, II, xiii, §365).

${ }^{2}$ In the Blue Book, Wittgenstein states quite clearly that the historical process by which a notion is acquired does not have a philosophical relevance: "Teaching as the hypothetical history of our subsequent actions (understanding, obeying, estimating a length, etc.) drops out of our considerations. The rule which has been taught and is subsequently applied, interests us only so far as it is involved in the application. A rule, so far as it interests us, does not act at a distance." ( $B B: 14)$

3 This point is obvious, but it has never really been made in the case of Spengler. Quite puzzlingly, many people have stressed the similarities shared by Spengler and Wittgenstein (FERBER 1991; TURANLI 2005 : 75 and 83) whereas the fundamental divergences (BOUVERESSE 1990) opposing them are rarely taken into account. Despite the fact that Wittgenstein emphatically criticized Spengler at the beginning of the 30s, Stanley Cavell claimed in an influential paper (i.e. "Declining Decline: Wittgenstein as a Philosopher of Culture") that Wittgenstein's Philosophical Investigations are more open minded towards Spengler's ideas (CAVELL 1989 : 256). Inspired by this suggestion, De Angelis has tried to show that we should interpret Wittgenstein's later philosophy of language in Spenglerian terms (2009). These attempts seem to be wide of the mark, because Wittgenstein has always rejected the idea of an historical necessity, which constitutes the fundamental assumptions of all Spengler's philosophy. - For a reconstruction of Wittgenstein's criticism of Russell and Odgen and Richard, see (ENGELMANN 2013 : 68-89). 
fleshed out (§ 1). 2/I establish that the Ethological Account seems to be committed to a metaphysical view according to which historical and diachronic necessities do not exist (§ 2). 3/I argue that Wittgenstein cannot reject the idea of historical necessity and endorse the Ethological Account without holding a self-defeating position (§ 3). 4/Finally, although the upshot might not seem very Wittgensteinian, I will flesh out an alternative formulation of the Ethological Account, which seems to be more philosophically appealing. This will lead me to put forward an unorthodox reading of the notion of "grammatical rule" that makes room for a robust conception of diachronic necessities.(§ 4).

\section{The Ethological Account of Language Acquisition}

Ethology is the science that studies human and animal behaviours. Therefore, the ethological account of language can be defined as follows: our use of language cannot be explained without taking into account some ethological facts about human behaviour. In Philosophical Investigations, the ethological account of language is introduced when Wittgenstein tries to understand how words can refer to a private and inner sensation. As it is usually the case with Wittgenstein, he does not answer that question, but he goes on by asking a slightly different question that he considers just as equivalent: "This question is the same as: How does a human being learn the meaning of names of sensation? For example, of the word 'pain'." Once the question has been reframed in such a way, Wittgenstein unfolds what many scholars have considered as the "ethological account" allegedly fleshed out by Philosophical Investigations:

Here is one possibility: words are connected with primitive (ursprünglichen), natural, expressions of sensation and used in their place. A child has hurt himself and he cries; then adults talk (sprechen) to him and teach him exclamations and, later, sentences. They teach the child new pain-behaviour. "So you are saying that the word "pain' really means crying?" - On the contrary: the verbal expression of pain replaces (ersetz) crying, it does not describe it $(P I, \S 244)$.

When we take this passage at its face value, the very idea that it contains any "theory" about language acquisition seems to be farfetched. As Wolgast has rightly pointed out in PI $\$ 244$, Wittgenstein is only making a claim about the acquisition of the word "pain". For that reason, it is not clear at all that we can infer a general theory of language from what he says about the particular 
case of "pain". If we consider that the passage just quoted implies a fullblown theory of the acquisition of all sensation concepts, this account appears to be false and "extravagant" (WOLGAST 1994 : 590). For instance, it is difficult to conceive how Wittgenstein's description can explain how notions such as "feeling of coldness", "seeing" or "hearing" are actually learned by children. Nevertheless, it is clearly possible to develop a nonextravagant reading of Wittgenstein's remark. Indeed, one can still hold the view that it is not possible to recognize the soundness of Wittgenstein's remark about "pain" without attributing to him a general view regarding the relation of language and behaviour.

So, even if the extravagant reading of $P I \S 244$ is ruled out, one can still claim that Wittgenstein is committed to an ethological account of language acquisition. Basically, this argument runs as follows: Wittgenstein's remark about pain would not be cogent unless he endorses four theses, which are constitutive of the ethological account:

1. The Pragmatic Thesis (PT). Language is a practical activity that is supposed to have some pragmatic effects. One can easily gather from $P I \S 244$ that "I have pain" should not be considered as a "description" of a mental state. According to Wittgenstein, "a cry is not a description" (PI, II, ix, §83). Consequently, if the sentence "I have pain" actually "replaces" a cry and fulfills its function, it does not make any sense to treat it as a description ${ }^{1}$. "I have pain" is not a description based on a self-observation, but it actually corresponds to a kind of "reaction" $(P I, \S 659)$. In other words, "I have pain" should be understood as a kind of behaviour or action. As Wittgenstein puts it, learning to use the sentence "I have pain" boils down to learning a new kind of "pain-behaviour" $(P I, \S 244)$. This strain of thought leads to a highly anti-intellectualist analysis, which defines the meaning of psychological expressions as mainly practical. Canfield phrases Wittgenstein's pragmatic approach that way: "Learning to talk is learning to act. The actions constituting speech are continuous with such performances as manipulating, crawling or walking" (CANFIELD $1993: 172$ ).

2. The Overlap Thesis (OT). Actions and linguistic signs are not mutually exclusive categories. Although it is not the case that all

${ }^{1}$ Of course, there are degrees between the cry and the pure description. Depending on the utterance context, an assertion like "I have pain" or "I'm afraid" can be more or less close to a simple cry. (PI, II, ix, §73 and §83) 
actions are linguistic signs, these two notions overlap. In order to hold $O T$, one should thus claim either that linguistic signs are a kind of behaviour or that some natural behaviour constitutes a kind of language. Following Wittgenstein's account, linguistic signs are a kind of action and, accordingly, he endorses a possible version of OT. Of course, Wittgenstein does not want to conflate the distinction between behaviour and verbal language. Linguistic signs are governed by grammatical rules, whereas instinctive and primitive behaviour are not. However, it would be misleading to understand this distinction in too rigid a way. The difference between natural behaviour and linguistic signs does not imply that they cannot overlap. "Words are also deeds" $(P I, \S 546)$, writes Wittgenstein. From that standpoint, linguistic signs may have a behavioral dimension because some of our languagegames would not be possible without our instinctive behaviours. Then, the relation between language and behaviour is not a relation of identity ${ }^{1}$. Linguistic signs are the product of the "extension" (Ausbau) $(Z, \S 545)$ or the "refinement" (Verfeinerung) $(C V$, p. 31) of natural behaviour made possible by the mastering of social conventions.

3. The Logical Relation Thesis (LRT). The relation between the notion of pain and the behavioural expression of this mental state is not a contingent one. According to Wittgenstein, it would be logically impossible to acquire the notion of pain without natural and instinctive

\begin{abstract}
${ }^{1}$ Danielle Moyal-Sharrock holds a version of the identity thesis according to which verbal expression is a subspecies belonging to the behaviour category: "The word, exclamation, or sentence assimilated as a replacement of the natural expression is itself behaviour. It is not a clearer, more eloquent description of the sensation, but constitutes an alternative expression of the sensation-an alternate mode of behaviour: 'the verbal expression [Ausdruck] of pain replaces crying and does not describe it' (WITTGENSTEIN 1997 : 244). So that where we use words in the place of groans, this replacement does not entail a categorical change, but only a change of manner or manifestation." (2000 : 361) Since I want to give the more plausible version of the Ethological Account, I do not attribute to their proponent this thesis that seems to be highly controversial and problematic. Indeed, such a view leads to a purely expressivist understanding of "I have pain" that leads to the traditional problem pointed out by Geach (1965). If "I have pain" is a cry without any propositional content, this means that such an expression cannot be used in logical reasoning. Therefore, the identity thesis implies that it does not make sense to say something like "I have pain, hence I will take an aspirin". Norman Malcolm speaks rather of an analogical relation between pain-behaviour and "I have pain" (1982:17). We will stick to that weaker version of $O T$.
\end{abstract}


behaviour $(P I, \S 257)$. One cannot attribute pain sensations to a rock, whereas it appears to be impossible to deny that a wrangling flea is suffering due to that logical connection between pain and painbehaviour (PI, §284). As Wittgenstein puts it: "It amounts to this: that only of a living being and what resembles (behave like) a living being can one say: it has sensations; it sees; is blind; hears; is deaf; is conscious or unconscious" $(P I, \S 281)$. Of course, it is possible to have pain without expressing it in any kind of behaviour: I can certainly have pain and try to hide it. The opposite is also true: I can fake pain by mimicking typical pain-behaviours. However, these possibilities do not break the logical relation of pain and pain-behaviour previously mentioned. If pain was never expressed in behaviour, we would not be able to explain and teach how to use "pain". From this cogent observation, Wittgenstein will rightly draw the conclusion that there is a "logical" relation between an inner mental state and its behavioural expression: "The inner is tied up with the outer not only empirically, but also logically" (LWPP II : 63). Proponents of the ethological reading (HARRE \& ROBINSON) usually interpret this logical relation as a relation of foundation. "Pain" is logically related to painbehaviour in the sense that my use of the notion "pain" is grounded on the existence of pain-behaviours. According to Zettel \$541, a pattern of behaviour is said to be "primitive" and "pre-linguistic" when a language game is grounded (beruht) on it. Thus, pain is logically related to pain-behaviour because it would not be possible to use pain in the language-game of pain ascription without the existence of painbehaviour ${ }^{1}$.

4. The Genetic Thesis (GT). The relation between pain-behaviour and "pain" is not only a logical one. Wittgenstein underlines rightly in PI $\$ 244$ that pain-behaviour is "replaced" by the sentence "I have pain". Hence, pain-behaviour and "I have pain" are related historically. Children cry and, after we taught them to do so, they will express their pain by using words and sentences. Moreover, Wittgenstein is also committed to the claim that a particular temporal order should be followed in the concept learning process. For instance, the notion of doubt is learned after the notion of certainty (PO, Cause and Effect :397). Likewise, Wittgenstein argues that lying is a language-game

\footnotetext{
1 According to Malcolm, it is, for instance, "logically impossible" that a stone has pain (1989: 101) because there is a logical relation between the concept of pain and pain-behaviours.
} 
that must be learned and is chronologically posterior to the truthful expression of inner state. It does not make sense to believe that the smile of a baby is untruthful $(P I, \S 249)$ because it is impossible to imagine a child lying systematically ( $P O$, Notes for Lectures on "Private Experience" and "Sense-data" :217). At first, children use language as a way to express their inner life truthfully and, after, they learn to lie to other people.

\section{The Genetic Thesis Clarified}

As I already mentioned at the beginning of this paper, it is not clear at all that Wittgenstein is actually committed to the Ethological Account. As a matter of fact, Wittgenstein uses a conditional form in PI $\$ 244$ ("one could say") suggesting that he does not himself hold the view he is stating ${ }^{1}$. Furthermore, Wittgenstein does not seem to be committed to the Logical Relation Thesis. Indeed, Wittgenstein states explicitly $(P I, \S 142)$ that it is possible to imagine that people, who do not have pain-behaviours, can learn the language-game of pain. Of course, such a possibility constitutes an "abnormal case" of the pain language-game. Still, it does not constitute a full-blown logical impossibility ruled out by the grammar of our language ${ }^{2}$. Consequently, Wittgenstein does not seem to believe that it is not possible to conceive an alternative form of life in which "pain" is not based on pain-behaviour.

1 This is not a knockdown argument against the Ethological Account. Hacker has convincingly shown that Wittgenstein uses the conditional form because he had in mind other similar possible cases that are nevertheless compatible with the Ethological Account (HACKER 1990 : 39). Hacker mentions that Wittgenstein says that we can teach someone by pinching him.

2 "And if things were quite different from what they actually are - if there were, for instance, no characteristic expression of pain, of fear, of joy; if rule became exception, and exception rule; or if both became phenomena of roughly equal frequency — our normal language-games would thereby lose their point. - The procedure of putting a lump of cheese on a balance and fixing the price by the turn of the scale would lose its point if it frequently happened that such lumps suddenly grew or shrank with no obvious cause." (My emphasis, $P I$, §142) This key passage states clearly that we can imagine a possible world in which we have a notion of pain, even though we did not naturally express our pain. Of course, the pain language-game would have a different point and a different practical significance, but it constitutes a genuine logical possibility. Such an idea contradicts frontally $L R T$. 
Although these exegetical issues are highly interesting, it is not the aim of this paper to engage in that kind of technical discussion. No matter if Wittgenstein actually endorses the Ethological Account, it is fairly evident that it constitutes an influential position that has been more or less loosely inspired by some patterns of Wittgenstein's thought. Once the exegetical question has been put aside, the philosophical question remains: does the Ethological Account give us a coherent and plausible explanation of language acquisition?

One of the main difficulties comes from the Genetic Thesis. It is rather difficult to understand what the grammatical nature of statements describing the history of language acquisition is. When Wittgenstein says that the acquisition of the notion of "appearance" is chronologically posterior to the learning of "being", is this statement of a (grammatical) necessity or a mere description of some empirical and natural facts? This question is extremely hard to answer. On the one hand, it is quite tempting to read Wittgenstein's remark about the learning of language as a kind of transcendental argument about the diachronic necessities conditioning any possible language. Indeed, it is difficult to understand the universality and the generality of Wittgenstein's claim about language learning without assuming that the Ethological Account relies on a substantial conception of necessity according to which every language needs to follow a necessary development in order to be a language. I read Norman Malcolm's version of the Ethological Account as an instance of that kind of philosophical position. PI $\S 244$ would then be interpreted as stating a logical necessity about the meaning of the notion of pain $^{1}$. On the other hand, the case has been frequently made for an empirical reading of GT. For instance, Moyal-Sharock does not believe that the behavioural origin of our language constitutes a sort of universal logical necessity. She rather makes the point that the Genetic Thesis shows that our language is "conditioned" by a set of empirical facts about our human form of life ${ }^{2}$. Similarly, it is fairly obvious that Canfield considers GT as a purely empirical claim and not as a metaphysical or a logical one ${ }^{1}$.

1 According to Malcolm, grammatical rules are true propositions describing the logical necessities which constitute the meaning of a concept (1982:21). In short, Malcolm considers that instinctive and primitive reactions constitute the condition of possibility of any language: "This confident going on in the same way, without any doubt, cannot be given any rational foundation. This is a reason for calling it 'instinctive'. Without this kind of natural agreement, this instinctive going on in the same way, there could not be language" (1982:16).

2 Moyal-Sharrock holds that hinges do not have a transcendental status (2004:60). Thus, the belief that our language is an extension of instinctive behaviours 
Given the therapeutic and the non-theoretical focus of the method used by Philosophical Investigations (KUUSELA 2008; HORWICH 2012), the very idea that Wittgenstein made transcendental claims about the structure of any possible language does not seem very attractive, exegetically speaking ${ }^{2}$. In the particular case of diachronic necessities, the transcendental reading appears to be even more unlikely. As a matter of fact, the transcendental reading collides with a powerful argument that Wittgenstein has developed against historical necessity while he was reading Oswald Spengler's Decline of the West. Since this argument is embedded in some general considerations stemming from Wittgenstein's philosophy of history that is remotely connected to the main issue of PI $\S 244$, proponents of the Ethological Account rarely explain why one should pick out the empirical interpretation of $G T$. The goal of this section is to remediate to that situation and make the anti-metaphysical assumption of the Ethological Account more explicit.

According to Wittgenstein, the idea of "historical necessity" does not line up with our own experience of history. Such a view relies on an important premise that played a major role in the Tractatus. One of the major ideas put forward by Wittgenstein in this book is that all necessities are logical necessities $(T, 6.37)$. This view entails, of course, that historical necessity is either a logical necessity or a philosophical myth invented by metaphysicians. Once the question has been framed that way, it is easy to guess on which side Wittgenstein will stand. Far from following a logical or a deductive order, history is full of surprises due to its essential contingent nature. Thus, one cannot claim that history has "logic" without falling into a kind of category mistake. History cannot work like logic. Due to its a priori nature, logic excludes any possibility of surprise: "There can never be surprises in logic" ( $T, 6.1251)$. In contrast to logic, history involves unpredictable elements that historians usually call "turning-point" or "epochmaking" events. Hence, stipulating that history has "logic" misses the unpredictable nature of historical becoming. As I have just mentioned, this

constitutes a "certainty" that does not derive from a substantial necessity. This certainty is rather causally conditioned by some empirical facts concerning the world and our human nature (2004:83).

1 "Wittgenstein's later philosophy has an empirical component, and that, in fact, it can provide a conceptual framework for a scientific study of language acquisition" (1995: 195).

${ }^{2}$ Bernard Williams (1974 : 92) and Jonathan Lear (1982:386) have defended this view. Unfortunately, this transcendental view does not square with the fact Wittgenstein considers that logical necessities are the product of arbitrary rules (FORSTER $2004: 24$ ). 
argument flows from the Tractatian conception of logic. However, the main focus of that book is not philosophy of history. For that reason, texts of the middle period (1931-37) like the Big Typescript and Philosophical Grammar are very important because, at this time, Wittgenstein has developed an extensive critique of Spengler spelling out more clearly why the idea of historical necessity should be rejected.

First of all, it is important to explain more precisely what Wittgenstein means by "surprise". A surprise happens when my expectation about reality conflicts with some empirical facts. For instance, if I hold the belief that no vegetation lives in the North Pole, I would be fairly surprised to learn that "Mr. Smith flew to the North Pole and has seen tulips all around" (LFM 1939 : 18). In a nutshell, there is room for surprise when I endorse a hypothesis that can collide with reality. According to the definition laid down by Philosophical Grammar, a hypothesis is an "image" that can be true or false by agreeing or contradicting reality ( $P G$, Appendix VI : 219). In Wittgenstein's wording, "A hypothesis is a law for forming propositions. You could also say: a hypothesis is a law forming expectations" ( $P G$, Appendix VI : 219). When I formulate the hypothesis that the North Pole does not have any vegetation, I formulate a law that allows me to construct a set of propositions ("There are no tulips on the North Pole", "No vegetation can grow on the North Pole because of the weather", etc.) expressing expectations that might be confirmed or deceived by reality. There is room for surprises only when expectations about empirical reality can be deceived. Thus, I can be surprised when the relation I have with reality implies hypotheses.

Following this account of surprise, mathematics ${ }^{1}$ and logic cannot be surprising. They do not rely on hypotheses that can be confirmed or infirmed

1 In the case of mathematics, Wittgenstein's position is trickier than one might expect. In Lectures on the Foundation of Mathematics, Wittgenstein says that mathematics cannot surprise us. Although mathematical paradox might be puzzling, it does not make any sense to say that mathematical discoveries are "surprising" (LFM 1939 :17-18). However, this distinction is a difference of degree and not of kind. In the Big Typescript, Wittgenstein states that the geometrical physic (i.e. geometry used by psychical science) involves hypotheses, which makes room for surprise. In Remarks on the Foundations of Mathematics, Wittgenstein goes a step further by saying that a mathematical paradox or the deepness of mathematical investigations count as a kind of "surprise" ( $R F M$, Appendix II, §1). When he makes that disturbing concession, Wittgenstein states clearly, however, that surprise is not prompted by a conflict between mathematics and reality. In the case of mathematics, the surprise does not come from the discovery of new facts, but from a lack of 
by empirical facts or perceptual experience ${ }^{1}$. Mathematical and logical truths cannot be surprising because they reflect grammatical rules. Indeed, one cannot be surprised by the fact that a square is a geometrical figure having four sides because it is a consequence of the grammar of the grammatical definition of "square". So, the core of Wittgenstein's argument is the idea that "Surprises do occur in the world, but not in grammar" $(B T, \S 15: 52)$.

This thesis is motivated by two different kinds of considerations. $1 /$ Grammatical rules express logical necessities. The negation of a grammatical rule is then a logical impossibility. For instance, I cannot imagine a square with five sides because a square with five sides is logically impossible. Since the alternative is logically impossible, the negation of a grammatical rule is a meaningless proposition that does not constitute a genuine possibility ( $P O$, Wittgenstein's Lectures : 60). Granted that the possibility of my being wrong is not a real possibility, it would be absurd to claim that I can be proven wrong and be "surprised" regarding the validity of a grammatical rule. 2/Grammatical rules cannot contradict reality because the function of grammar is to determine how a proposition can be compared to reality $(P G, \S 55: 97)$. In that respect, it does not make sense to say that grammar of "square" may collide with reality $(P G, \S 68: 111)$. The function of grammar is to provide rules that will allow us to understand which kind of object can be called a square. One cannot compare grammar with reality and eventually be surprised or deceived because any comparison between a piece of language and reality is made possible by grammatical rules themselves. For that reason, grammatical rules do not make room for something unforeseen $(Z, \S 296)$.

No matter if Wittgenstein is right to claim that all necessities are the product of a grammatical rule (I do not want to get entangled in that kind of issue in the present paper), history is clearly an empirical domain full of surprises that cannot be compared to logic or mathematics. Indeed, history is an empirical discipline relying on a whole range of hypotheses that might be contradicted by reality. As a matter of fact, expectations about the historical becoming of humanity are so often deceived, that it led historians to consider that it was vain to speculate about the future of humanity like philosophers of history used to do. It is then tempting to say that the very grammar of

understanding (RFM, Appendix II, §2). Consequently, mathematics are not "surprising" unless I do not really understand the mathematical concepts I'm dealing with $(R F M, \mathrm{I}, \S 68)$.

1 Concerning the lack of hypothesis in mathematics, see (BT, §108: 371). Wittgenstein makes a similar claim about logic $(B T, \S 54: 205)$. 
"history" presupposes its unpredictability. This crucial point is made by Wittgenstein in Culture and Value: "When we think of the world's future, we always mean the place it will reach if it keeps going as we can see it going in now; it does not occur to us that its path is not a straight line but a curve, constantly changing direction" ( $C V, 1929: 3)$. Wittgenstein does not deny that we cannot give a general picture of the course of history. In a way, we have a legitimate and undefeatable expectation about history, namely that our expectation about the future will necessarily be deceived. Contrary to natural sciences like physics and chemistry, the surprising nature of history seems to be so essential that we could foresee that all our predictions can be deceived. Surprise can certainly happen in every empirical domain, but one might say that history is probably the field where surprise happens more frequently. Thus, history would not be history if it was foreseeable and followed the course of a rational deduction.

The fact that history is unpredictable does not mean that we should give up all expectations about the future. We could not be social agents without having those expectations. If historical narratives make sense to us, it is mainly because the succession of historical events is not a purely irrational chaos. We can rightly have rational expectations about the future of the world, but we are never on a firm ground as in logic. History is not like a logical deduction because we have to deal with the partly surprising and unpredictable nature of the course of history. Given the surprising nature of history, we need to use hypotheses and confront them with empirical facts. Wittgenstein is then committed to the view that history can be approached with a large set of rational models, though none of these models can provide us with an indefeasible prediction. Historical predictions are then hypotheses suggested by our present experience. Because what we have experienced so far is $\mathrm{Y}$ and $\mathrm{Z}$, it makes sense to think that $\mathrm{X}$ will happen in the future even though a change of direction is always possible. We do not know the future; any hypothesis about the general direction of historical becoming could turn out to be wrong. However, even if this were the case, such an outcome does not necessarily mean that I have made a rational mistake, and that I should have made a different prediction. When a hypothesis is infirmed by the turn of events, it only means that a new model or a new narrative is needed in order to make sense of what has happened. My hypothesis was wrong because things have changed, and history has surprised me by starting to follow a different path.

Thus, the fact that $G T$ is a historical proposition about the chronological stages of language acquisition has to be taken very seriously. Remarks about the history of language acquisition of a given speaker must 
have the same grammar as any historical proposition. In short, a historical proposition can always be defeated and we cannot exclude the logical possibility of the surprise. Hence, the historical remark that "I have pain" is an extension of primitive reactions constitutes a true description of an empirical and contingent fact concerning how we, human beings, learn language. It is then not logically impossible that a different form of life has a similar notion of "pain" which does not originate from some primitive reactions. For instance, we can imagine people that are born with a mastery of the "pain" notion or that have learned it with the help of a computer program such as in the case of The Matrix.

In order to capture more precisely what has been said in this section, the Genetic Thesis should then be rephrased that way:

$G T^{*}$ : The use of "I have pain" is chronologically posterior to primitive painbehaviours because the former is an extension of the latter. However, this remark is meant to describe some empirical and contingent facts regarding the historical process by which we actually learn "pain". It is certainly possible that things might have been otherwise or will change in the future, but, for the time being, it is true that "I have pain" is an extension of our primitive reactions.

\section{The Ethological Account Reconsidered}

At first glance, the idea that the learning language process is "historical" seems to be harmless. However, combined with the empirical interpretation of the Genetic Thesis $\left(G T^{*}\right)$, the grammar/history dichotomy raises serious difficulties. If historical necessity does not exist, any historical succession of events is contingent. In the particular case of language acquisition, denying historical necessity makes room for the idea that it was not necessary that "I have pain" is a historical extension of the cry of a child. Of course, "I have pain" originates from a cry. Nevertheless, this empirical truth is contingent and constitutes a hypothesis. In other words, $G T^{*}$ describes a contingent fact about language acquisition that can change in the future.

This conclusion is embarrassing because it conflicts with another feature of the Ethological Account. Indeed, Wittgenstein is also supposed to endorse the Logical Relation Thesis (LRT) according to which it would not be possible to learn to use "pain" to a child who did not have any kind of pain behaviour. Thus, $L R T$ implies that the relation between pain behaviour and "I have pain" is not a hypothetical, but a necessary one. The existence of 
"pain behaviour" is the condition of possibility of "I have pain". Indeed, I cannot make sense of this relation of foundation if I do not also believe that my pain-concept is historically subsequent to my pre-linguistic pain behaviours that I had when I was a speechless child. It would be fairly puzzling to say that "pain" is necessarily grounded on "pain behaviour" if it was actually possible that a child learns a language game before having any kind of pain behaviour. Keeping these considerations in mind, it turns out to be impossible to give a coherent formulation of the Ethological Account while denying the existence of historical necessity. "I have pain" can only be logically grounded on pain-behaviour if "I have pain" is, historically speaking, the necessary extension of pain behaviour.

One promising way to solve this paradox is to show that it relies on an over simplistic understanding of Wittgenstein's concept of surprise. The possibility of surprise is not infinite because the notion of "surprise", like any other notion, is governed by some grammatical rules. Some phenomenon can be said to be a surprise whereas others cannot. Even though history can surprise us, there is a limit to how history can be surprising. In that respect, it is possible to interpret the genetic thesis not as a defeasible empirical claim, but rather as a grammatical rule limiting the evolution of any possible language. Such a view would not be a transcendental reading of the Genetic Thesis because we still stick to the idea that grammatical rules are arbitrary and strictly conventional. This grammatical approach is certainly in tune with some remarks made by Wittgenstein in Philosophical Grammar. For instance, when Wittgenstein argues that grammar does not involve surprise, he makes a remark about the grammar of what we usually mean by an "evolution" or an "expansion" of our language:

"But the language can expand" - Certainly; but if this word "expand" has a sense here, then I know already what I meant by it. I must be able to specify how I imagine such an expansion. And what I can't think, I can't now express or even hint at. And in this case the word "now" means: "in this calculus" or "if the words are used according to these grammatical rules" (PG, §71:114).

Our language can certainly evolve and expand itself. Yet this evolution cannot surprise me because the expression "expansion" has a particular meaning that is determined by the grammatical rules governing its use. For instance, the English language "expands" by the introduction of new words. However, I cannot imagine that English will expand by introducing rules of declension or a new kind of pronoun. That kind of evolution does not correspond to what we usually mean by the "expansion" of a modern 
language. If that kind of transformation happened to English, we would be probably inclined to speak of a new language. After all, English itself comes from a transformation and a blend of different languages (mainly German and French). To say that the expansion of language cannot alter the main grammatical structure of the language is not to make an empirical hypothesis about the future of English language. It is rather a way to remind us that the word "expansion" must follow some rules in order to make sense.

Accordingly, when Wittgenstein makes claims about the historical evolution of a language, one does not have to read them as empirical hypotheses. For instance, when Wittgenstein says that an individual could not have invented the practice of playing games even if he can invent a particular game, he is not formulating an empirical hypothesis about the history of the invention of games. In fact, Wittgenstein's point is rather to state that the historical hypothesis just mentioned is nonsensical and does not reflect the grammar of what we call "games". If a singular person could have invented the institution of playing games, our very notion of "game" would have had a different meaning. Playing games is a social practice which is tied-up to the natural history of human beings. Consequently, it is logically impossible to imagine that a singular person has invented the very idea of playing a game. Thus, the grammar of "game" has a diachronic and historical dimension. When I invent a game, I must follow some particular rules, which are different to those I follow when I invent a new language or a new tool. This historical evolution is determined by the actual grammar of the language because I want to call what I'm inventing a "game". In other words, when I invent a new game the possibility range is limited by grammatical rules governing some words like "games", "evolution", etc.

Similarly, "language learning" must follow a particular succession in order to be called so. In that respect, when Wittgenstein says: "II have pain' is historically derived from pain behaviour", he is stating a rule of grammar. "I have pain" would have a different meaning if it was not a replacement and an extension of some primitive reactions like cries. Even if Wittgenstein rejects metaphysical and historical necessity, he is not committed to the view that the learning language process is completely arbitrary and unpredictable. The grammar of "learning" and "language" implies that such a process must follow some necessary steps in order to be called a "learning language process". If it was possible to learn the meaning of "pain" without showing at least some pain-behaviour, the notion of "pain" would be fully different. Thus, the Genetic Thesis is not a historical hypothesis, but a necessary truth similar to " $\mathrm{A}=\mathrm{A}$ " or "A chessboard is made of 64 squares". 
Unfortunately, this grammatical solution to the internal contradiction of the Ethological Account seems to be a non-starter for a reason related to Wittgenstein's own definition of grammar. According to Wittgenstein's account, a grammatical rule is supposed to be the product of an arbitrary convention $^{1}$. Therefore, the narrative constitutive of the ethological account should be treated as such. This conclusion has two straightforward consequences. 1/If the narrative of the ethological account is a grammatical rule, this narrative cannot be confirmed or infirmed by empirical facts. This is clearly not in line with what Wittgenstein says about language acquisition in PI 244 . For instance, if ethology achieved to show that natural reactions are not involved in "pain" learning, such a discovery would be a massive argument against Wittgenstein's account ${ }^{2}$. Similarly, it seems hard to imagine that a historical narrative about language acquisition cannot be confirmed by some historical facts. When someone teaches his child the use of "I have pain", it looks like an empirical confirmation of Wittgenstein's claim. Saying the contrary seems to overlook the fact that Wittgenstein's narrative is convincing because it is based on some strong empirical evidence. 2/If Wittgenstein's narrative was a grammatical rule; one should draw the conclusion that a different concept of language would have come with a different historical narrative. Thus, it would be perfectly possible to imagine an alternative notion of pain, which is not an extension of some natural reactions. Following that train of thought, one could claim that we had chosen to define language as a conventional practice stemming from instinctive reaction, although there is no grammatical or philosophical necessity involved in that choice. Our language is grounded on instinctive behaviour, but if we wanted to do so, we could certainly have constructed abstract languages completely cut off from any kind of natural reaction. Of course, such a view undermines the interest of the Ethological Account because it would not do the philosophical work it is supposed to do. The Ethological Account is meant to make a general claim about the fact that any pain language-game would not be possible without primitive reactions on which they are grounded. By trivializing Wittgenstein's position, the idea that historical necessities are constituted by grammatical rules leads us to a relativist conception of language evolution that fails to take into account the strong and substantial intuition voiced by PI $\$ 244$ according to which no

1 "The only correlate in language to an intrinsic necessity is an arbitrary rule" ( $P G$, $\S 133)$.

${ }^{2}$ For instance, in a fictive scenario similar to 2001: Space Odyssey, one can imagine that we have learned psychological concepts by touching a monolith. 
psychological concepts could have been invented or learned, if human beings did not express naturally their mental states.

It should be clear by now that the Ethological Account faces an impossible dilemma because of the rejection of historical necessity. From a Wittgensteinian standpoint, only two possibilities are available: either $G T$ is $1 /$ an empirical proposition describing a contingent fact or 2/ a grammatical rule constituted by an arbitrary convention. Thus, the contingency of empirical propositions or the arbitrariness of grammatical rules, undermines the substantial claim made by the Ethological Account, i.e. that "I have pain" comes necessarily of an extension of some primitive reactions (LRT). Accordingly, the only way to safeguard the substantial claim made by the Ethological Account seems to consider that it describes a universal necessity, which holds true for any possible language. Following this line of thought, saying that verbal behaviour is an extension of primitive reaction is stating a necessary condition of any possible language. In other words, $G T$ has to be grounded on a full-blown necessity presupposed by any historical narrative about the language learning process. Of course, the philosophical price to pay for endorsing a coherent version of the Ethological Account is pretty high for a Wittgensteinian: the idea that necessary truths about language evolution correspond to arbitrary rules cannot be maintained. The next section will try to establish if it is possible to make sense of this alternative formulation of the Ethological Account in a Wittgensteinian framework.

\section{A Case for a non-empirical reading of $G T$}

The difficulty encountered by the Ethological Account spelled out in the previous section is well known. As a matter of fact, it constitutes a new formulation of a fairly usual objection made against conventionalism. In 1936, C. D. Broad made an objection of that kind against Ayer (1936 : 71), who claimed that necessary truths were analytical propositions instituted by conventional rules. Board's objection is straightforward: if necessary truths originate from contingent and empirical facts about the use speakers make of their language, one should draw the conclusion that necessary truths are not really necessary, but contingent $(1936$ : 107). Reducing necessary truths to a matter of verbal definition, the conventionalist is at risk of undermining the necessity that he wants to explain. Aware of this difficulty, Norman Malcolm tries to meet this serious concern (1940) with a loosely Wittgensteinian strategy that might be used, as we shall see later on, to develop a more satisfying version of the Ethological Account. 
First of all, it is important to bear in mind the reason why philosophers like Wittgenstein and Ayer conceive necessary truths as conventional definitions ${ }^{1}$. One of the main complaint about the metaphysical conception of necessary truth is its lack of clarity. In that respect, the example of Broad is particularly illuminating. According to Broad, necessary truths are supposed to have a self-obvious character, which can be immediately grasped by the mind. Though Broad's account of a priori knowledge makes room for a complex taxonomy (a distinction between intuitable and demonstrable a priori is made (1936 : 103)), he is committed to the view that at least some necessary truths can be grasped by an act of intuition. As Malcolm points out, this account is fueled by the idea of an occult and mysterious act of intuition that, far from clarifying the concept of necessity, makes it more obscure (1940: 192). Moreover, the idea that necessity can be grasped by an act of intuition is misleading because it moves us to believe that necessary truths are abstract objects described by necessary propositions (1940:203). Against such a view, Malcolm makes the point that we do not have to acknowledge the existence of a dubious faculty of intuition in order to make sense of the idea of necessary truths. Knowledge of necessary truth comes from the simple and empirical observation of how people think and speak. Differently put, I can grasp logical necessity by observing how language is normally used ${ }^{2}$. In order to grasp a necessary truth, I just have to take into account what is logically entailed by a proposition used by a given speaker ${ }^{3}$.

1 Hacker has made the point that it is misleading to present Wittgenstein, like Dummett does, as a full-blown conventionalist (2009 : 365). He also argues that Wittgenstein's has an account of necessary truths that does not line-up with the conventionalist account fleshed out by Ayer and Carnap. Once again, I do not claim to give an accurate picture of Wittgensteinian conception of necessity, although I do not subscribe to Hacker's reading which tends to downplay - in a nonWittgensteinian way - the arbitrary character of grammar (see $2009: 333$ ).

${ }^{2}$ Malcolm described the reasoning leading to the idea that philosophy is grammar in the following way: "The fact that a philosophical question of the form, 'does $p$ entail q ?' is to be answered by an examination of what people would say, of our actual use of the expressions in question, and in no other way, has led people to say, 'Philosophy is really grammar"' (1940:195).

3 "The procedure of seeing what a statement entails, the meaning of which is not clear, is not divisible into two processes-first, getting clear about its meaning, and second, seeing what it entails. It is the single process of getting clear about the meaning of the statement. And to get clear about its meaning is to find out how it is being used. And this is a matter to be settled by the eyes and ears through observing how the person who used it would react or what he would say if somebody else said 
In that respect, the idea that logic is grammar (1940: 198) might be "illuminating"; it discourages people to consider that necessary truths are abstract and occult entities grasped by an intuition. As Malcolm says in the title of one of his books (which is itself a reference to a passage of Philosophical Investigations): "Nothing is hidden".

Does that mean that Malcolm is committed to the view that necessary truths are constituted by arbitrary rules of grammar? No. The assimilation of necessary truths to grammatical rules is illuminating in the sense that it challenges a harmful picture of the nature of necessity put forward by Broad. Despite its illuminating character, Wittgenstein's grammatical conception of necessity can also be highly misleading. That is, Broad was perfectly right when he said that a conventionalist conception of necessity leads to conceive necessity as something contingent, which does not make any sense. Thus, saying that "necessary truths are grammatical rules" is stating something false and misleading (1940:200). There is a huge difference between a proposition expressing a necessary truth (" $2+2=4$ ") and an empirical proposition about the use of these signs ("In English, speakers generally answer ' 4 ' when we ask them what the result of ' $2+2$ ' is"). Nevertheless, the idea that logic is made of grammatical rules has a therapeutic value. Necessary truths are not mere grammatical conventions, but the analogy between grammar and necessity leads us on the right track. Necessary truths are not grasped by an occult act of intuition, but they show themselves in the use we make of the language. The notion of grammar helps us to be aware that necessities are not facts or abstract objects.

According to Malcolm, the conventional nature of necessary propositions should not be taken literally, even if Ayer or Wittgenstein probably wanted their readers to do so $(1940: 203)$. When Wittgenstein says that necessities are grammatical conventions, it is important to keep in mind that such an affirmation is mainly meant to dissolve a nest of problems related to the traditional understanding of necessary truths. In other words, the goal is to produce an aspect-switch that will discourage philosophers to think of necessity as a kind of abstract entity grasped by an intuition. Once the danger of thinking of necessity as metaphysical entities is cleared of the way, the analogy between necessities and grammar rules can be put aside or relativized. This remark is of course of the higher importance in the present context. According to Malcolm, the vocabulary of grammar can be gave up if it is judged preferable to tackle a particular philosophical problem by using

something of a certain sort, and so on. And so by this procedure we learn necessary truths" (1940 : 197). 
terms such as "essence", "logical necessities" and "necessary truths"1. This choice of terminology depends on the philosophical problem that needs to be dissolved.

This Malcolmian approach can certainly be used in the case of Wittgenstein's attitude towards historical necessity. As the example of Spengler shows, the idea of historical necessities is highly misleading. According to the Decline of the West, historical necessity is a metaphysical reality (namely a "destiny" (1927 : 129)) that can only be grasped through the mediation of a non-discursive and non-rational "intuition" 2 . This idea comes with a controversial claim according to which historical becoming is governed by a kind of "organic logic" (1927 : 117). In the context of a discussion of Spengler's conception of historical necessities, the idea that history does not have a logical form, as well as the thought that necessary truths are grammatical rules, are particularly illuminating. Still, as our critical discussion of the Ethological Account have made it plain, the bold rejection of historical necessities is misleading because it undermines the necessary relation that "pain" entertains with pain-behaviours. The misleading character of Wittgenstein's critique of Spengler lies in the fact that it transforms a necessity into something either contingent or arbitrary. Thus, in the particular context of the discussion of the Ethological Account, it is a strategic error to choose that kind of vocabulary. Unsurprisingly, Malcolm does not phrase his own accounts in terms of empirical facts or grammatical rules, and he rather talks about "logical necessity", "logical possibility" and "logical impossibility". For instance, when he states that we are highly reluctant to attribute pain to a stone, he argues that such an attribution is "logically impossible". The thought is not that we cannot attribute pain to a stone because no rules have allowed us until now to make that kind of pain-

\footnotetext{
${ }^{1}$ As a matter of fact, Malcolm strongly relies on the vocabulary of On Certainty. Not only does he present the Ethological Account as a logical necessity, be he claims that it is based on a kind of "certainty" (1984:13-17). Given the scope of this paper, I decided to put this aspect of Malcolm position aside because it is impossible to take into account without engaging in an overall interpretation of Wittgenstein's latest work. Following Moyal-Sharrock's vocabulary, I believe that one can legitimately consider that Malcolm's reading of On Certainty implies that $G T$ is not an empirical claim, but a universal hinge (MOYAL-SHARROCK 2004 : 148). In other words, GT is a certainty constitutive of the ability of human beings to use language.

${ }^{2}$ This intuitive method is inspired by Goethe. (SPENGLER $1928: 25$ )
} 
attribution. Quite on the contrary, the claim is that such an attribution is impossible given the very essence of what pain and mental states are ${ }^{1}$.

This argument is clearly based on one of the main trends of the Private Language Argument. According to Wittgenstein, pain-attribution is a normative practice. Like any rule-governed activity, it must be logically possible to make a distinction between believing in following a rule and following it effectively $(P I, \S 202)$. As Wittgenstein stresses, inner phenomena need exterior criteria $(P I, \S 580)$. No matter what the grammar of our language is, given our form of life, it would be logically impossible to make a difference between a correct use of "pain" and an incorrect one if human beings did not express naturally their pain in primitive and instinctive behaviours. Consequently, the very essence of the normativity of rules necessarily implies that our primitive and behavioural expression of pain constitutes the condition of possibility of our "pain" language-game. When we look at our normal use of "pain", this normativity is not always clear to see. That is the reason why Wittgenstein invites us to look at the way we teach that concept to a child. This pedagogical example shows the logical and necessary relation that "pain" has with pain-behaviours. In other words, the language learning process is not a parochial custom that could have been otherwise. The way we talk and think about language learning shows that "pain" comes necessarily after a primitive expression of pain. And it is precisely because the Genetic Thesis is a necessary truth that it is right to endorse the Logical Relation Thesis according to which there is a logical relation between "pain" and pain behaviour.

\section{Conclusion}

This paper has shown that any grammatical or empirical reading of the genetic thesis threatens the coherence of the Ethological Account. Malcolm's version does not seem to fall into this pitfall because he believes that necessary truths cannot be reduced to grammatical conventions. Consequently, if we adopt a non-reductionist conception of necessary truths, it is possible to give an alternative reading of the Genetic Thesis, which renders

${ }^{1}$ A cryptic passage of Philosophical Investigations ("Essence is expressed in grammar" $(P I, \S 371))$ opens the door to an interpretation of Wittgenstein along these lines. According to that passage, the relation between essence and grammar is not a relation of identity, but a relation of expression. Therefore, it is possible to argue that the notion of grammar does not imply a rejection of the notion of essence. 
the Ethological Account more philosophically plausible. I do not deny that it might be difficult to show that such an account reflects Wittgenstein's actual position. Nevertheless, I do not consider such an endeavour as completely impossible. Although Wittgenstein seems to give a huge importance to that notion of grammar, it is possible to show that this notion has a non-dogmatic and therapeutic dimension that makes room for Malcolm's critical stance towards it ${ }^{1}$. In any case, the goal of the paper was not to provide an accurate interpretation of PI $\$ 244$, but to assess the validity of some philosophical positions that it has inspired. Regarding this issue, the lesson of this paper is that the empirical reading of PI $\$ 244$ leads to serious philosophical difficulties undermining the validity of the Ethological Account taken as a whole. Since the rejection of historical necessities leads us to an untenable position, it gives us a serious reason to acknowledge the soundness of this notion. Indeed, it seems impossible to take seriously the strong philosophical intuition $^{2}$ expressed by the Ethological Account without following Malcolm and opening the door to some minimal historical necessities.

\section{Bibliography}

Baker, G. \& Hacker, P.M.S. 2005. Wittgenstein: Understanding and Meaning (Part I: Essays), Oxford and New York: Oxford University Press.

—, 2009. An Analytical Commentary on Wittgenstein's Philosophical Investigations. Rules Grammar and Necessity, v. 2, New York and Oxford: Blackwell.

Brenner, W.H. \& Moyal-Sharrock, D., 2005. Readings of Wittgenstein's on Certainty, New York: Palgrave and Macmillan.

Broad, C.D., 1936. "Symposium: Are There Synthetic A Priori Truths". Proceedings of the Aritotelian Society, Supplementary Volumes, 15, 102-153.

Bouveresse, J., 1990. "The Darkness of this time: Wittgenstein and the modern world". Royal Institute of Philosophy Supplement, 28, 11-39.

Cahill, K.M., 2009. "Bildung and Decline". Philosophical Investigations, 32(1), 24-43.

Canfield, J.V., 1993. "The living language: Wittgenstein and the Empirical Study of Communication". Language Sciences, 15(3), 165-193.

_, 1995. "The Rudiment of language". Language and Communication, 15(3), 195-211.

${ }^{1}$ Following the non-dogmatic reading of Kuusela (2008) (which relies strongly on Wittgenstein's remarks about Spengler's philosophy of history), it is possible to interpret the notion of grammar as an object of comparison.

${ }^{2}$ I use the term "intuition" in a non-technical sense. I am not committed to the view that intuition is a particular faculty grasping some metaphysical necessities. 
Cavell, S., 1988. "Declining decline: Wittgenstein as a Philosopher of Culture". Inquiry, 31(3), 253-264.

DeAngelis, W.J., 2007. Ludwig Wittgenstein- A Cultural Point of View, Burlington: Ashgate.

Dray, W., 1980. Perspectives on History, London: Routledge \& Kegan Paul.

Dromm, K., 2003. Imaginary Naturalism: the Natural and Primitive in Wittgenstein's later thought. British journal for the History of Philosophy, 11(4), 673-690.

-, 2006. Wittgenstein on Language-Learning. History of Philosophy Quarterly, 23(1), 79-94.

Drury, M.O., 1996. The danger of Words and writings on Wittgenstein, Wiltshire: Thoemmes Press.

Engelmann, M.L., 2013. Wittgenstein's Philosophical Development. Phenomenology, Grammar, Method, and the Anthropological View, Hampshire: Palgrave and Macmillan.

Ferber, R., 1991. Wittgenstein und Spengler. Archiv für Geschichte der Philosophie, 73(2), 188-207.

Forster, M., 2004. Wittgenstein on arbitrareness of grammar, Princeton and Oxford: Princeton University Press.

Frye, N., 1974. “'The Decline of the West' by Oswald Spengler”. Daedalus, 103(1), $1-13$.

Garver, N., "Form of life in Wittgenstein's Later Work". Dialectica, 44(1-2), 175-201.

Gier, N.F., 1981. Wittgenstein and Phenomenology, Albany: State University of New York Press.

Glock, H.-J., 1996. A Wittgenstein Dictionnary, Cambridge: Blackwell.

Grondin, V., 2010. "La préhistoire du sens. Les limites du dualisme de l'histoire et de la grammaire chez Wittgenstein”. Études philosophiques, (3), 363-375.

Harré, R. \& Robinson, D.N., 1997. "What Makes Language Possible? Ethological Foundationalism in Reid and Wittgenstein". The Review of Metaphysics, 50(3), 483-498.

Horwich, P., 2012. Wittgenstein's Metaphilosophy, Oxford: Oxford University Press.

Hunter, J.F.M., 1968. "Forms of life in Wittgenstein's Philosophical Investigations". American Philosophical Quaterly, 5, 233-243.

Kuusela, O., 2008. The Struggle against dogmatism: Wittgenstein and the Concept of Philosophy, London and Cambridge: Harvard University Press.

Kuusela, O. \& McGinn, M. éd., 2011. The Oxford Handbook of Wittgenstein, Oxford: Oxford University Press.

Lear, J., 1982. "Leaving the World Alone". Journal of Philosophy, 79(7), 382-403.

Loughlin, V., 2014. "Radical Enactivism, Wittgenstein and the cognitive gap". Adaptive Behavior, 22(5), 350-359.

Lurie, Y., 1989. "Wittgenstein on culture and civilization". Inquiry, 32, 375-397.

Malcolm, N., 1940. “Are necessary propositions really verbal?”. Mind, 49(194), 189-203. 
—, 1954. "Wittgenstein's Philosophical Investigations". The Philosophical Review, 63(4), 530-559.

-, 1982. "Wittgenstein: The Relation of language to Instinctive Behavior". Philosophical Investigations, 5(1), 1-22.

—, 1989. "Turning to stone". Philosophical Investigations, 12(2), 101-111.

McDonough, R.M., 2004. "Wittgenstein, German Organicism, Chaos, and the center of Life". Journal of the History of Philosophy, 43(3), 297-326.

McGuinness, B., 2002. "In the shadow of Goethe: Wittgenstein's intellectual project". European Review, 10(4), 447-457.

Moyal-Sharrock, D., 2000. "Words as deed: Wittgenstein 'spontaneous utterances' and the dissolution of the explanatory gap". Philosophical Psychology, 13(2), 355-372.

-, 2004. Understanding Wittgenstein's on Certainty, New York: Palgrave and Macmillan.

Neurath, O., 1973. Empiricism and Sociology, Dordrecht: D. Reidel Publishing Company.

Perrin, D., 2007. Le flux de l'instant, Paris: Librairie philosophique J. Vrin.

Rubinstein, D., 2004. "Language Games and Natural Reactions". Journal for the Theory of Social Behavior, 34(1), 55-71.

Spengler, O., 1927. Decline of the West, $t$. 1, New York: Alfred A Knopf.

Turanli, A., 2005. "Wittgenstein and Spengler vis-à-vis Frazer". Philosophy and Social Criticism, 31(1), 69-88.

Williams, B., 1974. "Wittgenstein and Idealism". Understanding Wittgenstein. London and Basingstoke: Macmillan.

Wittgenstein, L., 1958. The Blue and the Brown Books, Malden, Oxford and Victoria: Blackwell $(B B)$.

—, 1961. Tractatus Logico-Philosophicus, London: Routledge \& Kegan Paul (T).

—, 1967. Zettel, Oxford: Blackwell (Z).

- 1969. On Certainty, New York: Harper Torchbooks (OC).

-, 1975. Wittgenstein's Lectures on the Foundations of Mathematics. Cambridge 1939., Chicago and London: The University of Chicago Press (WLFM).

-, L., 1978. Remarks on the Foundations of Mathematics, Oxford: Basil Blackwell (RFM).

- 1979. Philosophical Grammar, Oxford: Basil Blackwell (PG).

-, 1979. Wittgenstein's Lectures. Cambridge 1932-35., Oxford: Basil Blackwell (WL1932-35).

-, 1980. Culture and value, Chicago: The University of Chicago Press (CV).

-, 1982. Wittgenstein's Lectures. Cambridge 1930-32, Oxford: Basil Blackwell (WL 1930-32).

—, 1993. Philosophical occasions, Indianapolis and Cambridge: Hackett Publishing company $(P O)$.

—, 2001. "The Big Typescript», Wien: Springer Verlag (BT).

—, 2009. Philosophical Investigations, Malden and Oxford: Wiley Blackwell (PI).

Wolgast, E., "Primitive Reactions". Philosophical Investigations, 17(4), 587-603. 